\title{
Mechanistic Aspects of Osmium(VIII) Catalyzed Oxidation of L-Tryptophan by Diperiodatocuprate(III) in Aqueous Alkaline Medium: A Kinetic Model
}

\author{
Nagaraj P. Shetti, Ragunatharaddi R. Hosamani, and Sharanappa T. Nandibewoor
}

P.G. Department of Studies in Chemistry, Karnatak University, Dharwad 580 003, India

Correspondence should be addressed to Sharanappa T. Nandibewoor, stnandibewoor@yahoo.com

Received 24 November 2008; Accepted 11 December 2008

Recommended by Wolgang Linert

In presence of osmium(VIII), the reaction between L-tryptophan and diperiodatocuprate(III) DPC in alkaline medium exhibits 1:4 stochiometry (L-tryptophan:DPC). The reaction shows first-order dependence on [DPC] and [osmium(VIII)], less than unit order in both [L-tryptophan] and [alkali], and negative fractional order in [periodate]. The active species of catalyst and oxidant have been identified. The main products were identified by spectral studies and spot test. The probable mechanism was proposed and discussed.

Copyright (C) 2008 Nagaraj P. Shetti et al. This is an open access article distributed under the Creative Commons Attribution License, which permits unrestricted use, distribution, and reproduction in any medium, provided the original work is properly cited.

\section{Introduction}

In the recent past [1], some relatively stable copper(III) complexes have been prepared, namely, the periodate, guanidine, and tellurate complexes. The $\mathrm{Cu}^{3+} / \mathrm{Cu}^{2+}$ reduction potential is $-1.18 \mathrm{~V}$ in alkaline solution [2]. The copper(III) periodate complex (DPC) exhibits different multiple equilibria involving different copper(III) species in aqueous alkaline medium. It is interesting to know which of the copper(III) species is the active oxidant.

L-tryptophan (L-trp) is an essential aminoacid and it is needed to maintain optimum health. Osmium(VIII) acts as an efficient catalyst in many redox reactions $[3,4]$ involving different complexities due to the formation of different intermediate complexes, free radicals, and multiple oxidation states of osmium.

The uncatalyzed reaction of oxidation of L-tryptophan by DPC has been studied [5]. We have observed that the microamounts of osmium(VIII) catalyze the oxidation of L-trp by DPC in alkaline medium. In order to understand the active species of oxidant and catalyst and to propose the appropriate mechanism, the title reaction is investigated in detail, in view of various mechanistic possibilities.

\section{Experimental}

All chemicals used were of reagent grade and millipore water was used throughout the work. A solution of L-trp (s.d. fine) was prepared by dissolving an appropriate amount of recrystallized sample in millipore water. A stock solution of osmium(VIII) was prepared and standardized by the method reported earlier [6]. The copper(III) periodate complex was prepared [7] and standardized by standard procedure [8].

2.1. Kinetic Measurements. All kinetics measurements were carried out as in earlier work [6].

\section{Results and Discussion}

The results indicated 1:4 stoichiometry as given in Scheme 1.

The main product, indole-3-acetic acid, was separated by TLC, using the mixture of methyl acetate, isopropanol, and $25 \%$ ammonium hydroxide in the ratio of 45:35:20. IR, NMR spectra and its melting points were compared with the literature and were in good agreement. The LC-MS analysis of isolated product indicated the presence of indole-3-acetic acid as molecular ion peak, m/z 175. 


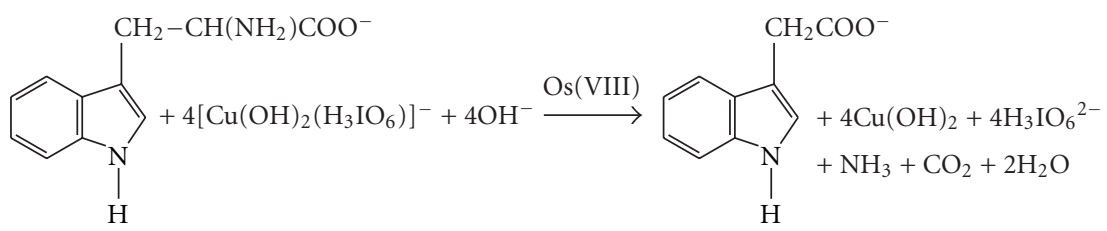

Scheme 1: 1:4 stochiometry of osmium(VIII) catalyzed oxidation of L-trp by DPC reaction.
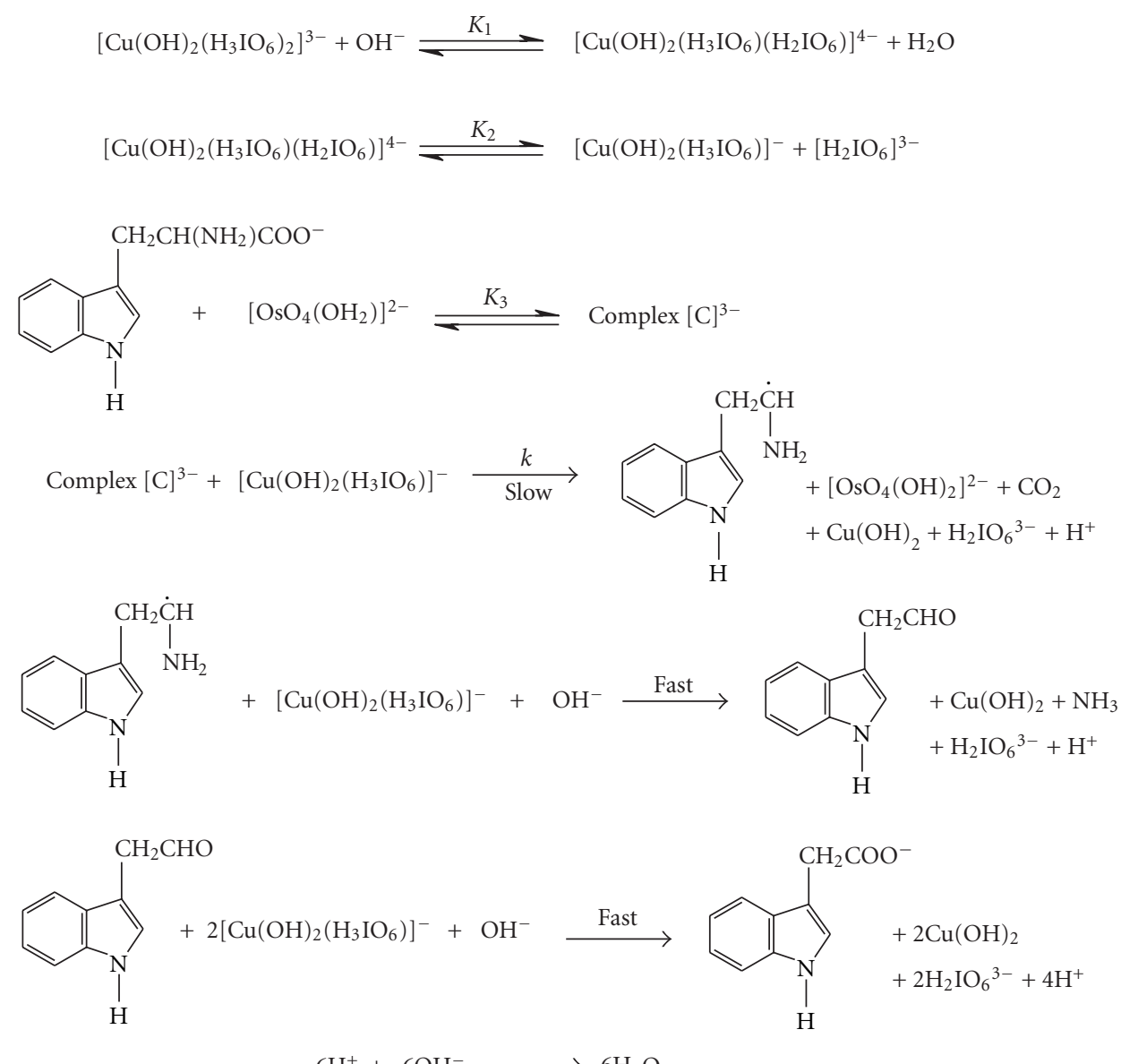

Scheme 2: The osmium(VIII) catalyzed oxidation of L-trp by DPC.

In the presence of catalyst, the reaction is understood to occur via parallel paths with contributions from the uncatalyzed and catalyzed paths. The total rate constant $\left(k_{T}\right)$ is equal to the sum of the rate constants of the catalyzed $\left(k_{C}\right)$ and uncatalyzed $\left(k_{U}\right)$ reactions. Hence, $k_{C}=k_{T}-$ $k_{U}$. The reaction orders have been determined from the slopes of $\log k_{c}$ versus $\log$ (concentration) plots by varying the concentration of L-trp, Os(VIII), $\mathrm{OH}^{-}$, and $\mathrm{IO}_{4}{ }^{-}$, in turn, while keeping the other concentrations constant. The order in both [DPC] and [Os(VIII)] was found to be unity. The order in [L-trp] and $\left[\mathrm{OH}^{-}\right]$was found to be less than unity, and in [periodate] to be negative and less than unity. It is well known that [9] Os(VIII) exists as $\left(\mathrm{OsO}_{4}(\mathrm{OH})_{2}\right]^{2+}$ in aqueous alkaline medium. It was found that the increase in ionic strength increased the rate of reaction and decrease in dielectric constant of the medium increased the rate of reaction. Initially added products did not have any significant effect on the rate of reaction. Test for free radicals indicated the participation of free radical in the reaction [6]. These experimentally determined orders and results could be well accommodated in Scheme 2.

Based on the experimental results, monoperiodatocuprate MPC was considered to be the active species of DPC complex. The fractional order with respect to Ltrp concentration indicates the formation of a complex 
TABLe 1: Effects of [DPC], [L-trp], $\left[\mathrm{OH}^{-}\right],\left[\mathrm{IO}_{4}^{-}\right]$, and $[\mathrm{Os}(\mathrm{VIII})]$ on the osmium(VIII) catalyzed oxidation of L-trp by DPC in alkaline medium at $298 \mathrm{~K}, \mathrm{I}=0.20 \mathrm{~mol} \mathrm{dm}^{-3}$.

\begin{tabular}{|c|c|c|c|c|c|c|c|c|}
\hline $\begin{array}{l}0^{5}[\mathrm{DPC}] \\
\left(\mathrm{mol} \mathrm{dm}^{-3}\right) \\
\end{array}$ & $\begin{array}{l}10^{4}[\mathrm{~L}-\mathrm{trp}] \\
\left(\mathrm{mol} \mathrm{dm}^{-3}\right)\end{array}$ & $\begin{array}{l}{\left[\mathrm{OH}^{-}\right]} \\
\left(\mathrm{mol} \mathrm{dm}^{-3}\right) \\
\end{array}$ & $\begin{array}{l}10^{4}\left[\mathrm{IO}_{4}^{-}\right] \\
\left(\mathrm{mol} \mathrm{dm}^{-3}\right)\end{array}$ & $\begin{array}{l}10^{6}[\mathrm{Os}(\mathrm{VIII})] \\
\left(\mathrm{mol} \mathrm{dm}^{-3}\right)\end{array}$ & $10^{2} k_{T}\left(\mathrm{~s}^{-1}\right)$ & $10^{3} k_{U}\left(\mathrm{~s}^{-1}\right)$ & \multicolumn{2}{|c|}{$10^{2} k_{C}\left(\mathrm{~s}^{-1}\right)$} \\
\hline & & & & & & & Found & Calculated \\
\hline 1.0 & 5.0 & 0.1 & 5.0 & 8.0 & 1.90 & 5.84 & 1.32 & 1.34 \\
\hline 3.0 & 5.0 & 0.1 & 5.0 & 8.0 & 1.91 & 5.81 & 1.34 & 1.34 \\
\hline 5.0 & 5.0 & 0.1 & 5.0 & 8.0 & 1.89 & 5.70 & 1.32 & 1.34 \\
\hline 7.0 & 5.0 & 0.1 & 5.0 & 8.0 & 1.96 & 5.75 & 1.39 & 1.34 \\
\hline 10 & 5.0 & 0.1 & 5.0 & 8.0 & 1.89 & 5.91 & 1.30 & 1.34 \\
\hline 5.0 & 1.0 & 0.1 & 5.0 & 8.0 & 0.61 & 1.34 & 0.47 & 0.44 \\
\hline 5.0 & 3.0 & 0.1 & 5.0 & 8.0 & 1.45 & 3.80 & 1.10 & 0.99 \\
\hline 5.0 & 5.0 & 0.1 & 5.0 & 8.0 & 1.89 & 5.70 & 1.32 & 1.34 \\
\hline 5.0 & 7.0 & 0.1 & 5.0 & 8.0 & 2.28 & 6.83 & 1.56 & 1.54 \\
\hline 5.0 & 10 & 0.1 & 5.0 & 8.0 & 2.69 & 8.82 & 1.81 & 1.75 \\
\hline 5.0 & 5.0 & 0.02 & 5.0 & 8.0 & 1.68 & 8.23 & 0.87 & 0.85 \\
\hline 5.0 & 5.0 & 0.06 & 5.0 & 8.0 & 1.72 & 6.59 & 1.05 & 1.13 \\
\hline 5.0 & 5.0 & 0.1 & 5.0 & 8.0 & 1.89 & 5.70 & 1.32 & 1.34 \\
\hline 5.0 & 5.0 & 0.15 & 5.0 & 8.0 & 1.96 & 5.19 & 1.45 & 1.39 \\
\hline 5.0 & 5.0 & 0.2 & 5.0 & 8.0 & 2.01 & 4.45 & 1.56 & 1.47 \\
\hline 5.0 & 5.0 & 0.1 & 1.0 & 8.0 & 2.92 & 11.44 & 1.77 & 1.83 \\
\hline 5.0 & 5.0 & 0.1 & 3.0 & 8.0 & 2.45 & 8.06 & 1.64 & 1.53 \\
\hline 5.0 & 5.0 & 0.1 & 5.0 & 8.0 & 1.89 & 5.70 & 1.32 & 1.34 \\
\hline 5.0 & 5.0 & 0.1 & 7.0 & 8.0 & 1.66 & 4.83 & 1.18 & 1.16 \\
\hline 5.0 & 5.0 & 0.1 & 10.0 & 8.0 & 1.37 & 3.72 & 0.99 & 0.98 \\
\hline 5.0 & 5.0 & 0.1 & 5.0 & 3.0 & 1.18 & 5.70 & 0.61 & 0.60 \\
\hline 5.0 & 5.0 & 0.1 & 5.0 & 5.0 & 1.57 & 5.70 & 1.00 & 0.96 \\
\hline 5.0 & 5.0 & 0.1 & 5.0 & 8.0 & 1.89 & 5.70 & 1.32 & 1.34 \\
\hline 5.0 & 5.0 & 0.1 & 5.0 & 10.0 & 2.94 & 5.70 & 2.37 & 2.29 \\
\hline 5.0 & 5.0 & 0.1 & 5.0 & 15 & 4.01 & 5.70 & 3.34 & 3.38 \\
\hline
\end{tabular}

between L-trp and osmium(VIII) species. Spectroscopic evidence for the complex formation between catalyst and substrate was obtained from UV-vis spectra of Os(VIII), Ltrp, and a mixture of both. A bathochromic shift of about $6 \mathrm{~nm}$ from $255 \mathrm{~nm}$ to $261 \mathrm{~nm}$ in the spectra of Os(VIII) was observed. The Michaelis-Menten plot also proved the complex formation between catalyst and reductant. Such a complex between a substrate and a catalyst has been observed in other studies [6].

Scheme 2 leads to the following rate law:

$$
\begin{aligned}
\frac{\text { Rate }}{[\mathrm{DPC}]} & =k_{C}=k_{T}-k_{U} \\
& =\frac{k K_{1} K_{2} K_{3}[\mathrm{~L}-\mathrm{trp}]\left[\mathrm{OH}^{-}\right][\mathrm{Os}(\mathrm{VIII})]}{\mathcal{R}},
\end{aligned}
$$

where $\mathcal{R}$ denotes $\left[\mathrm{H}_{3} \mathrm{IO}_{6}{ }^{3-}\right]+K_{1}\left[\mathrm{OH}^{-}\right]\left[\mathrm{H}_{3} \mathrm{IO}_{6}{ }^{3-}\right]+$ $K_{1} K_{2}\left[\mathrm{OH}^{-}\right]+K_{1} K_{2} K_{3}\left[\mathrm{OH}^{-}\right][\mathrm{L}$-trp] which explains all the observed kinetic orders of different species. The rate law (1) can be rearranged into the following form which is suitable for verification:

$$
\begin{aligned}
\frac{[\mathrm{Os}(\mathrm{VIII})]}{k_{c}}= & \frac{\left[\mathrm{H}_{3} \mathrm{IO}_{6}{ }^{3-}\right]}{k K_{1} K_{2} K_{3}[\mathrm{~L}-\operatorname{trp}]\left[\mathrm{OH}^{-}\right]}+\frac{\left[\mathrm{H}_{3} \mathrm{IO}_{6}{ }^{3-}\right]}{k K_{2} K_{3}[\mathrm{~L}-\operatorname{trp}]} \\
& +\frac{1}{k K_{3}[\mathrm{~L}-\operatorname{trp}]}+\frac{1}{k}
\end{aligned}
$$

According to (2), others being constant, the plots of $[\mathrm{Os}(\mathrm{VIII})] / k_{C}$ versus $1 /[\mathrm{L}-\operatorname{trp}], \quad[\mathrm{Os}(\mathrm{VIII})] / k_{C}$ versus $1 /\left[\mathrm{OH}^{-}\right]$, and $[\mathrm{Os}(\mathrm{VIII})] / k_{C}$ versus $\left[\mathrm{H}_{3} \mathrm{IO}_{6}{ }^{2-}\right]$ were linear as in Figure 1. From the intercepts and slopes of such plots, the reaction constants $K_{1}, K_{2}, K_{3}$, and $k$ were calculated as $(15.6 \pm 0.4) \mathrm{dm}^{3} \mathrm{~mol}^{-1}, \quad(3.3 \pm$ $0.10) \times 10^{-4} \mathrm{~mol} \mathrm{dm}^{-3}, \quad(0.71 \pm 0.02) \times 10^{4} \mathrm{dm}^{3} \mathrm{~mol}^{-1}$, $(3.2 \pm 0.04) \times 10^{3} \mathrm{dm}^{3} \mathrm{~mol}^{-1} \mathrm{~s}^{-1}$, respectively. The values of $K_{1}$ and $K_{2}$ obtained were in good agreement with previously reported values [10]. These constants were used to calculate the rate constants over different experimental conditions; when compared with the experimental $k_{C}$ values, they were 


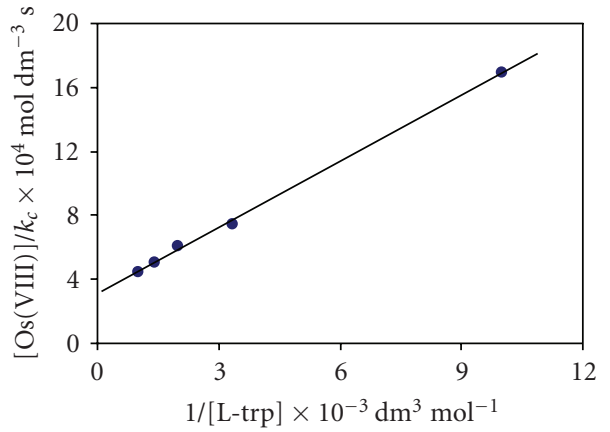

(a)

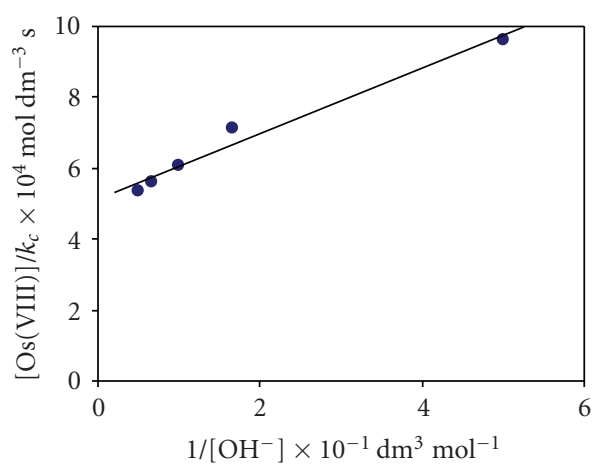

(b)

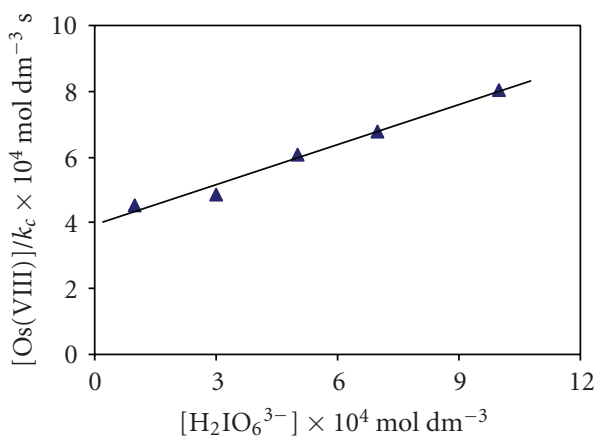

(c)

FIgURE 1: Verification of rate law (1) of Os(VIII) catalyzed oxidation of L-tryptophan by DPC at $298 \mathrm{~K}$ (conditions as in Table 1). (a) $[\mathrm{Os}(\mathrm{VIII})] / k_{c}$ versus $1 /\left[\mathrm{L}\right.$-trp]; (b) $[\mathrm{Os}(\mathrm{VIII})] / k_{c}$ versus $1 /\left[\mathrm{OH}^{-}\right] ;$(c) $[\mathrm{Os}(\mathrm{VIII})] / k_{c}$ versus $\left[\mathrm{H}_{2} \mathrm{IO}_{6}{ }^{3-}\right]$.

found to be in reasonable agreement with each other, which fortifies Scheme 2.

Similarly $K_{1}, K_{2}, K_{3}$, and $k$ were calculated at four different temperatures $(288,293,298$, and $303 \mathrm{~K})$ and used to compute the activation parameters and thermodynamic quantities. The values of $\mathrm{Ea}, \Delta H^{\#}, \Delta S^{\#}$, and $\Delta G^{\#}$ and $\log A$ were obtained and found to be $42.0 \pm 2 \mathrm{~kJ} \mathrm{~mol}^{-1}, 44.0 \pm 2 \mathrm{~kJ} \mathrm{~mol}^{-1}-30.0 \pm 1.5 \mathrm{~J} \mathrm{~K}^{-1} \mathrm{~mol}^{-1}$, $53.0 \pm 3 \mathrm{~kJ} \mathrm{~mol}^{-1}$, and $11.0 \pm 0.5$, respectively. (Ea, $\Delta S^{\#}, \Delta H^{\#}$, and $\log A$ were $51.7 \pm 3 \mathrm{~kJ} \mathrm{~mol}^{-1},-114 \pm 6 \mathrm{~J} \mathrm{~K}^{-1} \mathrm{~mol}^{-1}$, $48.2 \pm 2 \mathrm{~kJ} \mathrm{~mol}^{-1}$, and 10.5, resp., for the uncatalyzed reaction [5].) The catalyst Os(VIII) alters the reaction path by lowering the energy of activation (i.e., it provides an alternative pathway with lower activation parameters for the reaction).

The thermodynamic quantities, $\Delta H\left(\mathrm{~kJ} \mathrm{~mol}^{-1}\right), \Delta S$ $\left(\mathrm{J} \mathrm{K}^{-1} \mathrm{~mol}^{-1}\right)$, and $\Delta G\left(\mathrm{~kJ} \mathrm{~mol}^{-1}\right)$ using $K_{1}$ were calculated to be $-47,182$, and -6.4 , respectively. Similarly the values using $K_{2}$ were calculated to be $97.7,262.8$, and 18.6 , respectively and the values using $K_{3}$ to be $-144.0,-412.0$, and -22.0 , respectively.

The effect of ionic strength and dielectric constant of the medium on the rate explains qualitatively the reaction between two negatively charged ions, as seen in Scheme 1. The moderate $\Delta H^{\#}$ and $\Delta S^{\#}$ values are favorable for electron transfer reaction. The negative value of $\Delta S^{\#}$ suggests that the intermediate complex is more ordered than the reactants [11]. The observed modest enthalpy of activation and a higher-rate constant for the slow step indicate that the oxidation presumably occurs via an innersphere mechanism. This conclusion is supported by earlier observations [12].

\section{Conclusion}

Among various species of $\mathrm{Cu}(\mathrm{III})$ in alkaline medium, monoperiodatocuprate(III) is considered to be the active species for the title reaction. The active species of osmium(VIII) is understood to be as $\left[\mathrm{OsO}_{4}(\mathrm{OH})_{2}\right]^{2-}$. The activation parameters evaluated for the catalyzed and uncatalyzed reactions explain the catalytic effect on the reaction. The Os(VIII) catalyst alters the reaction path by lowering the energy of activation.

\section{References}

[1] L. Malaprade, "Synthesis and characterization of copper(III) periodate complex," Comptes Rendus, vol. 204, pp. 979-980, 1937.

[2] B. Sethuram, Some Aspects of Electron Transfer Reactions Involving Organic Molecules, Allied, New Delhi, India, 2003.

[3] F. A. Cotton and G. Wilkinson, Advanced Inorganic Chemistry, Wiley Eastern, New Delhi, India, 2nd edition, 1966.

[4] Ramalingaiah, R. V. Jagadeesh, and Puttaswamy, "Os(VIII)catalyzed and uncatalyzed oxidation of biotin by chloramine$\mathrm{T}$ in alkaline medium: comparative mechanistic aspects and kinetic modeling," Journal of Molecular Catalysis A, vol. 265, no. 1-2, pp. 70-79, 2007.

[5] N. P. Shetti and S. T. Nandibewoor, "Kinetic and mechanistic investigations onoxidation of L-tryptophan by diperiodatocuprate(III) in aqueous alkaline medium," Zeitschrift für Physikalische Chemie. In press.

[6] D. C. Hiremath, K. T. Sirsalmath, and S. T. Nandibewoor, "Osmium(VIII)/ruthenium(III) catalysed oxidation of Llysine by diperiodatocuprate(III) in aqueous alkaline medium: a comparative mechanistic approach by stopped flow technique," Catalysis Letters, vol. 122, no. 1-2, pp. 144-154, 2008.

[7] C. P. Murthy, B. Sethuram, and T. Navaneeth Rao, "Kinetics of oxidation of some alcohols by diperiodatocuprate (III) in alkaline medium," Zeitschrift für Physikalische Chemie, vol. 262, pp. 336-340, 1981. 
[8] G. H. Jeffery, J. Bassett, J. Mendham, and R. C. Denney, Vogel's Textbook of Quantitative Chemical Analysis, Longman, Essex, UK, 5th edition, 1996.

[9] Ramalingaiah, R. V. Jagadeesh, and Puttaswamy, "Os(VIII)catalyzed mechanistic investigation of oxidation of some benzimidazoles by chloramine- $T$ in alkaline medium: a kinetic approach," Catalysis Communications, vol. 9, no. 6, pp. 14431452, 2008.

[10] S. A. Chimatadar, A. K. Kini, and S. T. Nandibewoor, "Free radical intervention in the oxidation of sulfanilic acid by alkaline diperiodatocuprate(III) complex: a kinetic and mechanistic approach," Proceedings of the National Academy of Sciences India, vol. 77, pp. 117-121, 2007.

[11] A. Weissberger and E. S. Lewis, Eds., Investigations of Rates and Mechanism of Reactions, Techniques of Chemistry, John Wiley \& Sons, New York, NY, USA, 1974.

[12] S. A. Farokhi and S. T. Nandibewoor, "Kinetic, mechanistic and spectral studies for the oxidation of sulfanilic acid by alkaline hexacyanoferrate(III)," Tetrahedron, vol. 59, no. 38, pp. 7595-7602, 2003. 


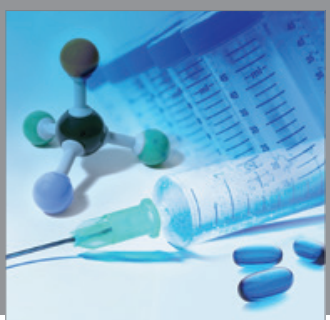

International Journal of

Medicinal Chemistry

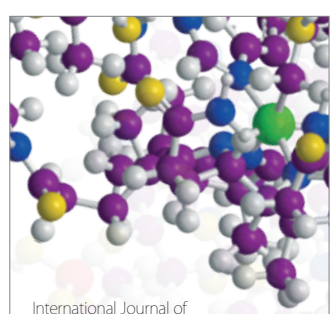

Carbohydrate Chemistry

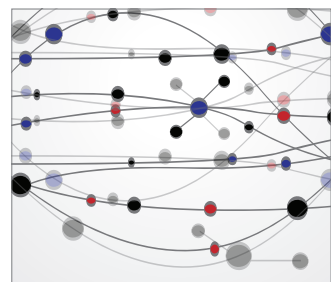

The Scientific World Journal
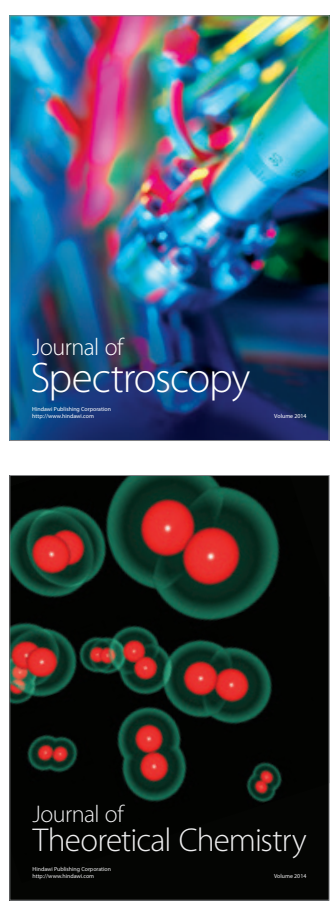
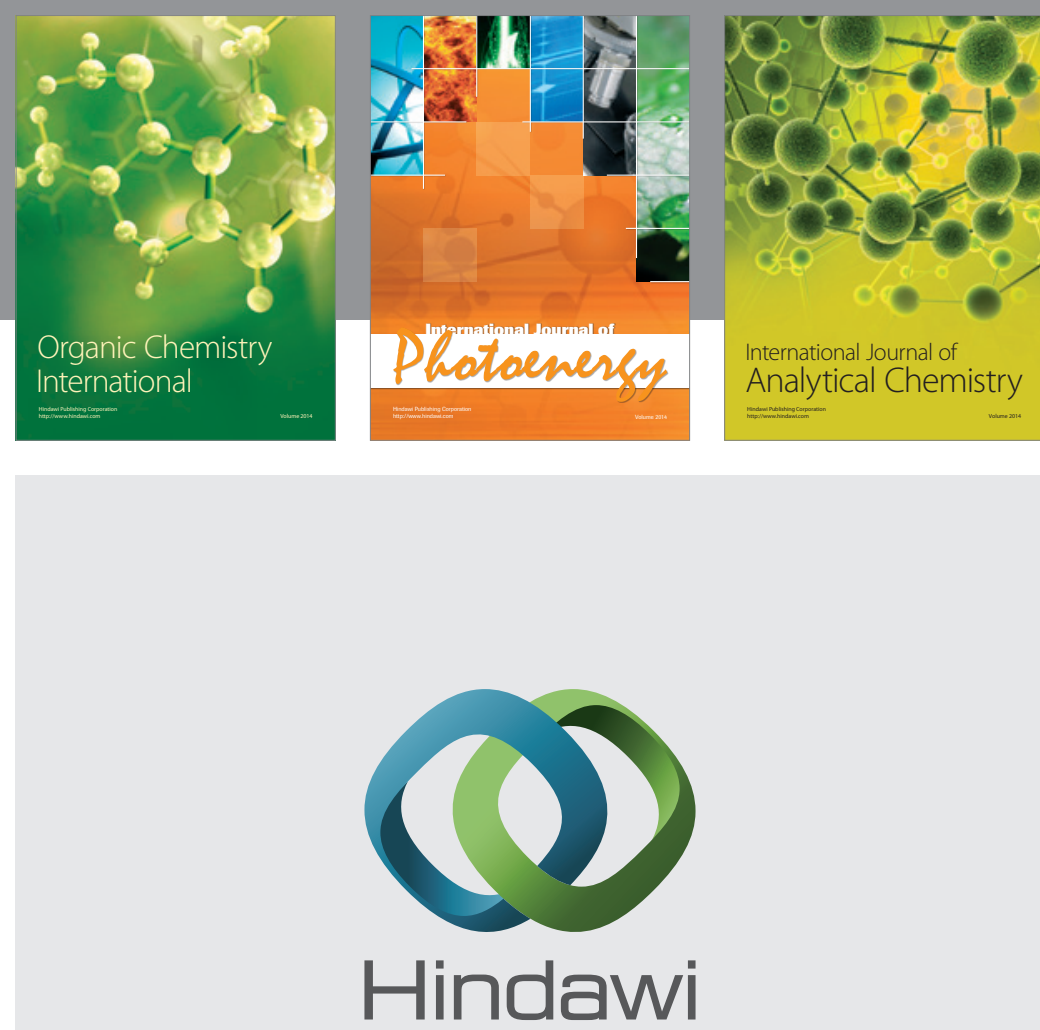

Submit your manuscripts at

http://www.hindawi.com
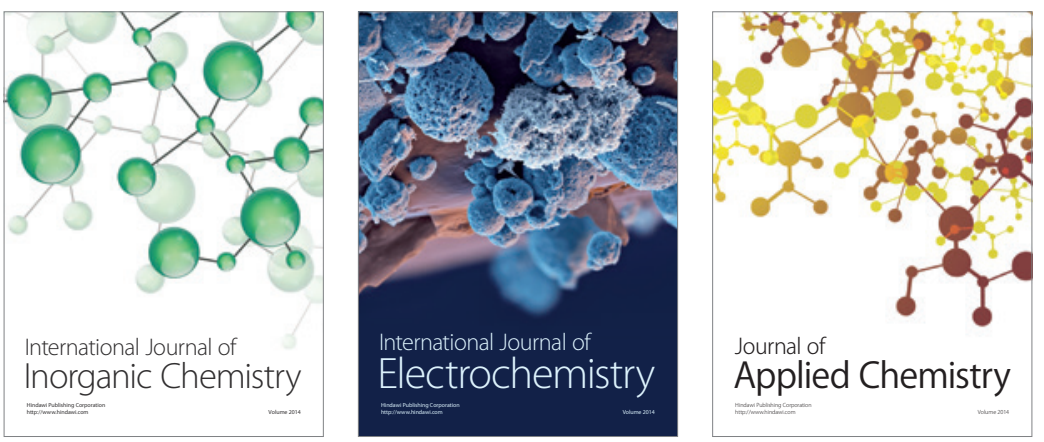

Journal of

Applied Chemistry
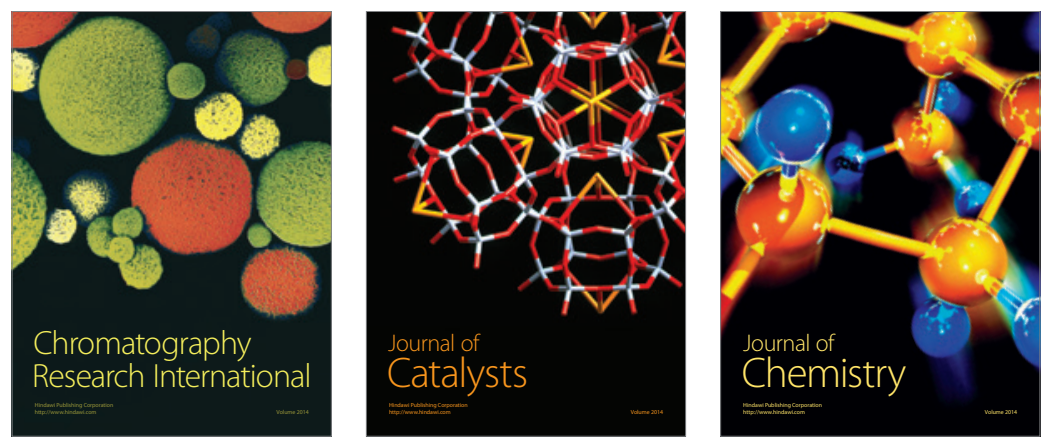
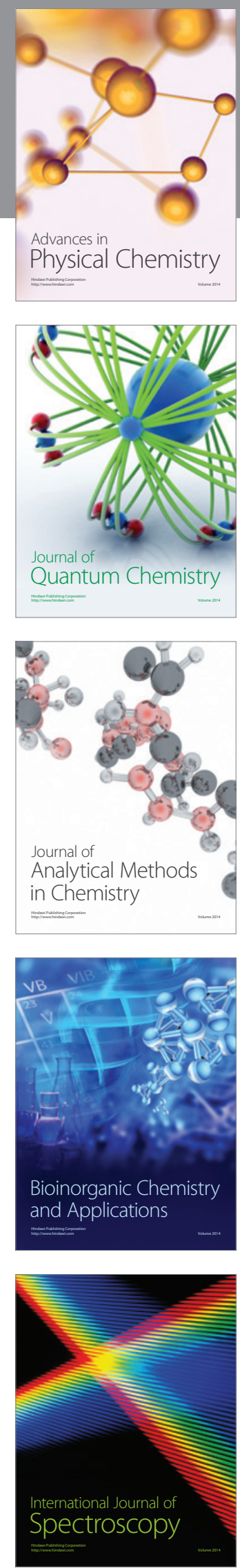